\title{
Optimal management of symptomatic os acromiale: current perspectives
}

This article was published in the following Dove Press journal: Orthopedic Research and Reviews

\author{
Ulrich J Spiegl' \\ Peter J Millett ${ }^{2}$ \\ Christoph Josten' \\ Pierre Hepp' \\ 'Department of Orthopedics, Trauma \\ Surgery and Plastic Surgery, University \\ of Leipzig, Leipzig, Germany; ${ }^{2}$ The \\ Steadman Clinic, Vail, CO, USA
}

\begin{abstract}
The majority of os acromiale is asymptomatic and requires no treatment. In patients with shoulder pain, os acromiale is a possibility in the differential diagnosis and may imitate shoulder impingement. The diagnosis of symptomatic os acromiale can be proven by combining physical examination, conventional radiographs, magnetic resonance imaging, and selective injections. Surgical treatment is indicated in those patients with failed conservative therapy, in those with highly painful and unstable os acromiale, or in those with associated shoulder pathologies such as rotator cuff tears. Open or arthroscopic excision is indicated in patients with pre-type os acromiale. In meso-type acromiale, arthroscopic excision, acromioplasty, or open reduction and internal fixation have all been used, but fixation is usually preferred. Internal fixation should be done either with cannulated screws alone or in combination with tension band, which has biomechanical advantages.
\end{abstract}

Keywords: os acromiale, nonoperative treatment, surgical treatment, open or arthroscopic excision, osteosynthesis techniques

\section{Anatomy}

The development of the acromion proceeds from many nuclei forming in the acromial apophysis, which was already described in $1933 .{ }^{1}$ These nuclei consolidate during adolescence to form three separate ossification centers along the periphery: the preacromion, where the coracoacromial ligament and the anterior origin of the deltoid is attached; the mes-acromion, which serves as the origin of the middle part of the deltoid muscle fibers; and the met-acromion, the origin of the posterior deltoid fibers. These three centers finally consolidate to form the acromion (Figure 1).

The exact time point of consolidation has not been determined precisely. Whereas some authors indicate that consolidation may not occur until 25 years of age, others have found that in one-third of cases consolidation had already occurred at the age of 14 years. ${ }^{2,3}$

\section{Epidemiology}

Os acromiale is described as a failure of osseous union between two of the apophyses; most commonly between the meso- and meta-acromion. ${ }^{4,5}$ Gruber $^{6}$ was the first who described os acromiale in 1863 . He described three cases of os acromiale in 100 cadavers. There seems to be a racial predispositions of os acromiale, with the prevalence in African-Americans varying between $11.1 \%$ and $20 \%{ }^{5,7}$ In contrast, the prevalence of os acromiale in the Korean population has been reported to be only $0.7 \%{ }^{8}$ In white 


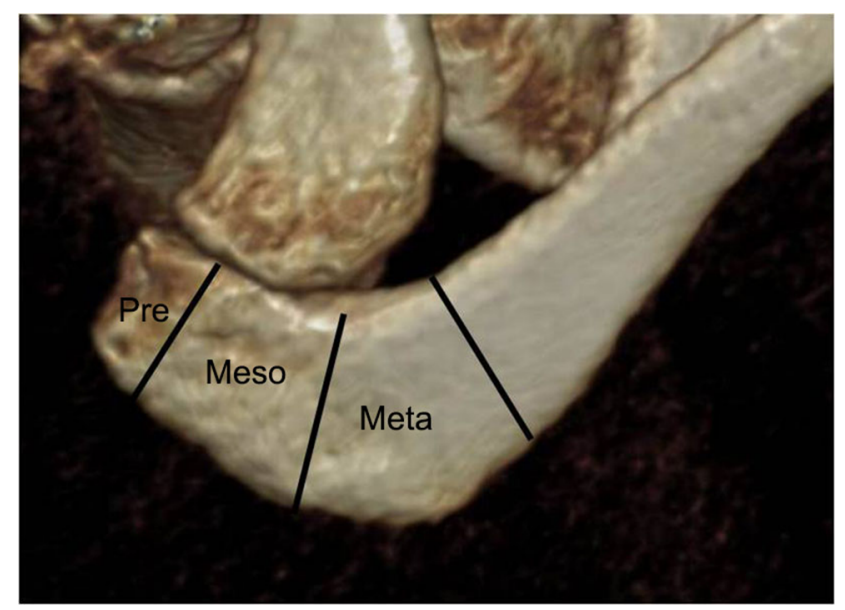

Figure I Three-dimensional reconstruction of the acromion including the lateral clavicle.

Note: The location of pre-, meso-, and meta-type os acromiale is shown.

people, the prevalence varied between $1.9 \%$ and $15 \% .^{7}$ The prevalence of os acromiale based on the more recent studies are summarized in Table 1. Generally, prevalence is higher in males, and more bilateral involvement has been reported, varying from between $30 \%$ and $62 \%$ of the individuals. ${ }^{14,15}$

\section{Clinical presentation}

Commonly, os acromiale is a nonsymptomatic condition which is identified incidentally during radiographic examination of the shoulder., ${ }^{414}$ Although symptoms may occur after minor or repetitive trauma, atraumatic origins are frequently seen. ${ }^{4,16}$ The age of diagnosis of symptomatic os acromiales range from adolescence to over 70 years. ${ }^{17,18}$ Tenderness over the anterolateral and lateral aspect of the acromion is very common. ${ }^{4,17}$ In some cases, gross motion can be detected. ${ }^{4}$ Patients frequently describe symptoms similar to subacromial impingement, including difficulty in overhead activities and pain while sleeping on the affected side. ${ }^{16,19}$ Anterior elevation of the shoulder is restricted in the vast majority of patients. Warner et $\mathrm{al}^{4}$ found restricted elevation, with less than $120^{\circ}$ of elevation in all of his patients. Impingement signs (Neer,
Hawkins) are common and provoke pain. In contrast, the acromioclavicular (AC) joint is not affected in the majority of the patients. Thus, neither pain on palpation at the AC joint nor a positive cross arm test is common. Shoulder strength is considerably reduced in the majority of patients with os acromiale. ${ }^{20}$

\section{Diagnostics}

Os acromiale is commonly visible on conventional radiographs, particularly on the axillary view. Lee et $\mathrm{a}^{21}$ described the double-density sign on the anteroposterior view and the supraspinatus outlet view that was highly suggestive of an os acromiale with a sensitivity of $82.4 \%$ and $94.1 \%$ and a specificity of $95.2 \%$ and $100 \%$, respectively. Additionally, computed tomography can be used to demonstrate incomplete fusion. However, it does not play a key role in the diagnosis because of its radiation exposure and insufficiency in detecting accompanying shoulder pathologies. Associated pathologies may range from tendinitis to full-thickness rotator cuff tearing. ${ }^{22}$ In contrast, magnetic resonance imaging (MRI) can be helpful to detect symptomatic os acromiale as it shows sclerotic and cystic changes as well as increased signal in the acromion and the surrounding soft tissue indicative of a mobile pseudarthrosis. The MRI is also helpful to demonstrate associated rotator cuff pathologies. Similarly, MRI is helpful to differentiate os acromiale from a normally developing acromial ossification center in adolescence. ${ }^{2}$ This can be difficult as acromial fusion is not completed in many cases in this age group. However, on MRI, a meso-acromion can be diagnosed by its transverse orientation and irregular margin with marrow and interface edema. ${ }^{2}$ In contrast, physiological developing acromial ossification centers have an arched interface and lobulated margins without evidence of marrow or interface edema. ${ }^{2}$ Furthermore, bone scans can be used to visualize symptomatic os acromiale in special situations by detecting the inflammatory response at the nonunion site of a meso-acromion. ${ }^{23}$

Table I Prevalence of os acromiale according to the studies published in year 2000 or later

\begin{tabular}{llll}
\hline Study & Population & Sample size & Prevalence (\%) \\
\hline Case et al ${ }^{9}$ & South African & 494 & 17.4 \\
${\text { Case et }\left.\right|^{9}}^{10}$ & Danish & 532 & 5.0 \\
Hunt et al $^{10}$ & White Americans & 766 & 5.4 \\
Kumar et al $^{7}$ & South Korean & 1,568 & 0.7 \\
Natsis et al & Germans & Native Americans (Coastal) & 1.9 \\
Ponce $^{12}$ & Native Americancs (Inland) & 52 & 7.7 \\
Ponce $^{12}$ & British & 90 & 5.5 \\
Roberts et al $^{13}$ & African-Americans & 86 & 1.2 \\
Sammarco & White Americans & 355 & 13.2 \\
Sammarco & & 843 & 5.8 \\
\hline
\end{tabular}


As a result of the unspecific presentation and the high number of asymptomatic cases, the diagnosis can be confirmed by injection of a local anesthetic at the site of os acromiale. This can be done with injection of $5 \mathrm{~mL}$ of $1 \%$ lidocaine with reexamination 10 minutes afterwards. ${ }^{24}$ This is an important confirmatory diagnostic tool to determine whether the os acromiale is the source of pain. ${ }^{20}$ Thereby, it is reasonable to perform a one-time corticosteroid injection in those patients who benefit temporarily from lidocaine injections. ${ }^{24}$

\section{Therapy Nonoperative strategies}

Nonoperative management is initially indicated in patients with symptomatic os acromiale. Based on the discrepancy between number of patients with symptomatic os acromiale and the relatively high prevalence of os acromiale, it seems to be obvious that nonoperative strategies can be useful. The authors believe that the reason for os acromiale not becoming symptomatic are the wide origin of the deltoid muscles at the lateral acromion and the lateral clavicle with overspreading muscle fibers across nonossified regions. Thus, anatomic stability exists in the majority of patients. In symptomatic cases' healing, the authors believe that healing occurs in some of the patients by optimizing the muscular balance of the affected shoulder including the scapular function. Additionally, corticoid injections often improve symptoms permanently. This should be particularly performed after successful diagnostic injections with local anesthetics. Generally, nonoperative therapy should last for at least 6 months. During this time, repetitive trauma that can be expected, ie, intensive overhead throwing activities or contact sports, should be avoided until symptoms are permanently gone. No data are available on whether further nontraumatic strategies such as pulsated ultrasound or shock wave therapy might be beneficial.

\section{Operative strategies}

In contrast, when nonoperative management fails, surgery is the next treatment option for symptomatic os acromiale. Several surgical techniques have been described, such as open or arthroscopic fragment excision, acromioplasty, ${ }^{24-27}$ and several techniques of open reduction and internal fixation (ORIF). Internal fixation can be done with cannulated screws alone or in combination with tension band, tension band wiring, $4,20,26,28-31$ and by arthroscopic resection of unstable fragments ${ }^{17,18,25,26,31-33}$ ORIF can be done with or without autologic (iliac crest bone graft) or allogenic bone graft (Table 2). ${ }^{20,26,32,33}$

Harris et $\mathrm{al}^{26}$ performed an interesting systematic review of the surgical treatment for symptomatic os acromiale in 2011 comparing fracture excision, arthroscopic as well as open, acromioplasty, and open reduction and fixation. They included at total of 9 studies including 118 patients and 125 shoulders. In the following paragraph, these results are summed up, updated with the results of more recent studies.

\section{Excision}

\section{Arthroscopic}

Studies comparing open and arthroscopic excision are unfortunately lacking. However, there are case series reporting the results of arthroscopic excision of os acromiale. Pagnani et $\mathrm{al}^{34}$ included 11 patients, aged between 18 and 25 years, with meso-type os acromiales. Excision of the os acromiale was done arthroscopically in all cases. All patients were able to return to sport by 14 weeks postoperatively. All patients demonstrated comparable shoulder strength to the contalateral side. Similarly, Wright et $\mathrm{al}^{27}$ performed arthroscopic excision in 12 patients (13 shoulders) with meso-type os acromiales. All patients demonstrated normal shoulder strength 6 months after surgery, with a satisfactory shoulder function in $92 \%$ of the patients. Campbell et a ${ }^{32}$ performed arthroscopic excision of meso-type os acromiale in 28 patients and a total of

Table 2 Surgical techniques for the treatment of symptomatic os acromiale

\begin{tabular}{llll}
\hline Surgical technique & Indications & Advantages & Disadvantages \\
\hline Open excision & Sympt. pre-ac. & No implants & r/o deltoid weakness \\
Arthrosc. excision & Sympt. pre + mes-ac. & No implants & Technical demanding \\
Acromioplasty & Sympt. pre + mes-ac. & No implants & Risk of fracture \\
ORIF: K-wires & Sympt. pre + mes-ac. & Low implant costs & Hardware removal risk of nonunion \\
ORIF: screws & Sympt. pre + mes-ac. & Low risk of implant irritation & Low stability in poor bone quality \\
ORIF: K-wires + tension band & Sympt. pre + mes-ac. & Low implant costs & Hardware removal \\
ORIF: screws + tension band & Sympt. pre + mes-ac. & Highest stability & Hardware removal often necessary \\
\hline
\end{tabular}

Abbreviations: Sympt., symptomatic; pre-ac., pre-acromion; r/o, risk of; mes-ac., mes-acromion; Arthrosc., arthroscopic; ORIF, open reduction and internal fixation. 
31 shoulders. The pain could be eliminated in 20 shoulders and reduced in 9 shoulders. In two shoulders (6\%), the pain was worse postoperatively. Similarly, no muscle weakness was detected in all patients.

\section{Open resection}

Boehm et $\mathrm{al}^{35}$ and Warner et $\mathrm{al}^{4}$ reported results of open excision with deltoid reattachment in pre-type and meso-type acromiale. Boehm et $\mathrm{al}^{35}$ found equivalent Constant scores and patient satisfaction versus age- and gender-matched controls. Warner et $\mathrm{al}^{4}$ described good outcomes after open excision in unstable pre-type os acromiale, whereas poor outcomes were seen in those patients with unstable meso-type os acromiale treated by open excision. Both of those patients had a history of failed open reduction and internal stabilization. Persistent shoulder weakness was the main concern in both of those patients.

\section{Acromioplasty}

Two studies compared the outcome of acromioplasty with ORIF in patients with unstable os acromiale. Both found no significant differences between both techniques. Two studies were designed retrospectively. First, Abboud et $\mathrm{al}^{25}$ performed arthroscopic cutting-block $(n=5)$ and open Neer $(\mathrm{n}=6)$ acromioplasty in 11 patients with meso-type os acromiale. They compared the outcome to patients who were treated by ORIF with either K-wires $(n=5)$ or cannulated screws $(n=3)$. Although patient satisfaction was greater in the acromioplasty group, the difference was not significant. Boehm et $\mathrm{al}^{35}$ compared patients undergoing open Neer acromioplasty versus internal fixation with $\mathrm{K}$-wires with or without bony fusion. Age- and gender-matched control comparison demonstrated equivalent Constant scores and patient satisfaction among all groups.

\section{Reduction and internal fixation}

As mentioned above, several fixation techniques have been described. Whereas Peckett et $\mathrm{al}^{30}$ reported a rate of union of $96 \%$ and a high satisfaction right (92\%) performing osteosynthesis with K-wires, screws, or tension wiring, Harris et $\mathrm{al}^{26}$ reported a significantly greater rate of radiographic healing after internal fixation using cannulated screws (96\%) compared to fixation with Kirschner wires (63\%) $(Z=2.735$; $99.7 \%$ confidence level). Thereby, the rate of radiographic healing correlated with significantly improved clinical outcome (University of California at Los Angeles Shoulder Score [UCLA Shoulder Score], American Shoulder and Elbow Surgeons [ASES] Score and patient satisfaction). Additionally, requirement for removal of internal fixation hardware was significantly greater after Kirschner wire fixation (88\%) versus after cannulated screw fixation (38\%) $\left(Z=4.181 ; 100 \%\right.$ confidence level). Warner et $\mathrm{al}^{4}$ performed open reduction including iliac crest bone graft in all patients with meso-type os acromiale. They reported of poor outcome after internal stabilization with tension band wiring with a union rate of only $20 \%$, whereas all patients treated by cannulated screws and tension band healed with solid union after an average of 9 weeks. Therefore, the authors recommended rigid fixation techniques including both cannulated screws and tension band. This could be proven biomechanically. Spiegl et $\mathrm{al}^{31}$ found significant higher failure loads after internal fixation with cannulated screws and tension band versus after cannulated screws alone in unstable meso-type os acromiale in a biomechanical set-up. Thereby, the authors found by trend higher failure loads after screw osteosynthesis in anterior-posterior direction compared to posterior-anterior direction during pilot testing. Therefore, the authors use this technique in patients with symptomatic

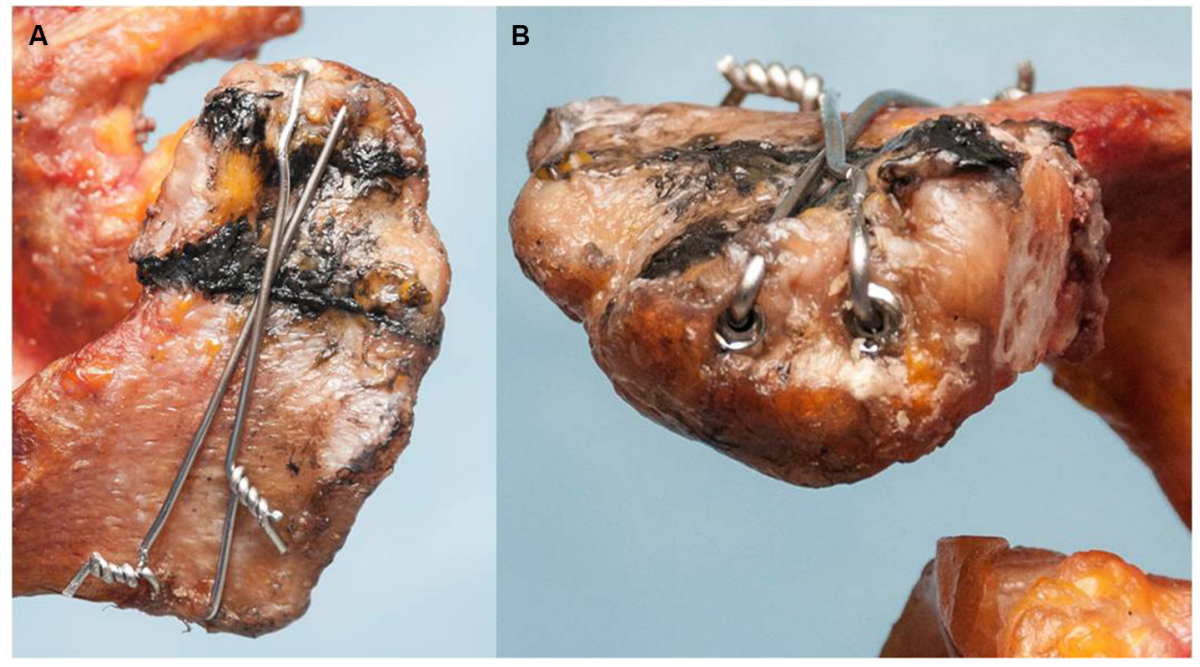

Figure 2 The technique of screw osteosynthesis with tension band is illustrated from cranial view (A) and anterior view (B). 


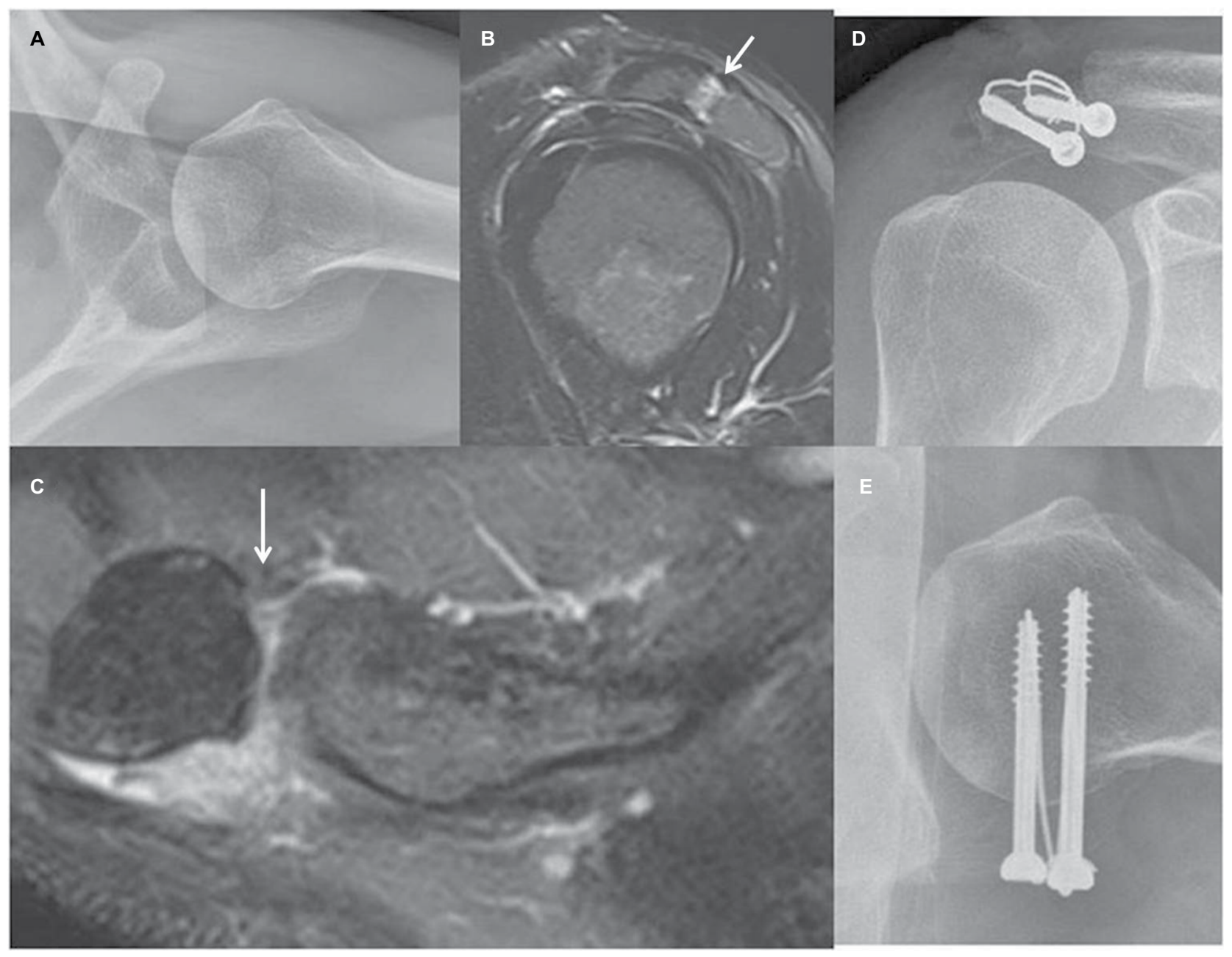

Figure 3 Radiograph of 43-year-old female with a history of I year of therapy-resistant pain at her right shoulder with pain on pressure on the right acromion.

Notes: A meso-type os acromiale is visible on the conventional axial radiograph (A). The MRI depicts edema at the region of the os acromiale (white arrows; B, C). Thus, resection of the pseudarthrosis and osteosynthesis with cannulated screws and tension band was performed (D, E). The patient was very satisfied 6 months postoperatively as she was without pain and had free shoulder function.

Abbreviation: MRI, magnetic resonance imaging.

meso-type os acromiale (Figures 2 and 3). Lebus et $\mathrm{al}^{36}$ just recently published this technique in detail describing the most important steps. The authors recommended an arthroscopic evaluation of the shoulder first to rule out any concomitant shoulder pathologies.

Just recently, Shiu et a ${ }^{37}$ found similar failure loads after internal fixation with cannulated screws and tension band with polyethylene suture compared to stainless steel tension bands and argued to use polyethylene suture band to avoid implant irritation that is commonly seen in patients with stainless steel tension band at the acromion.

\section{Surgical complications}

The rate of nonunion after internal fixation ranged between $0 \%$ and $100 \%$ depending on the fixation method. ${ }^{38,39}$ Additionally, Boehm et a ${ }^{35}$ reported their infection rate following surgical treatment of unstable os acromiale. The authors recorded four cases of deep infection (13\%) and two cases of superficial infection (6\%). One case of deep infection was following open excision $(17 \% ; 1 / 6)$, two cases following open acromioplasty $(40 \% ; 2 / 5)$, and one case following ORIF $(5 \% ; 1 / 22)$. Additionally, there were two cases of superficial infection following ORIF $(9 \% ; 2 / 22)$. Both of those healed without surgical revision using antibiotic therapy instead. As mentioned earlier, hardware removal was performed frequently after tension band wiring.

\section{Conclusion}

Generally, nonoperative therapy should be started, including physiotherapy, analgesia, and injections. Surgical treatment is indicated after failed conservative treatment. In patients with symptomatic pre-type os acromiale, open or arthroscopic excision might be the best therapeutic option leading to good outcomes. In unstable meso-type acromiale, several surgical 
techniques led to promising results, including arthroscopic resection, acromioplasty, and internal fixation. However, follow-up studies are missing, and definitive healing without the risk of recurrence can only be expected permanently in those patients with union at the site of os acromiale. Therefore, ORIF with bone graft seems to be the most promising technique, particularly in younger patients. This can be done with cannulated screws or in combination with tension band. Particularly in those patients with insecure screw hold and potential incompliancy, it might be advisable to perform a more rigid osteosynthesis combining cannulated screws with tension band. This can be done with stainless steel wiring or non-polyethylene sutures, potentially reducing the need for implant removal.

\section{Disclosure}

The authors report no conflicts of interest in this work.

\section{References}

1. Folliasson A. Un cas d'os acromial. Rev Orthop. 1933;20:533-538.

2. Winfeld M, Rosenberg ZS, Wang A, Bencardino J. Differentiating os acromiale from normally developing acromial ossification centers using magnetic resonance imaging. Skeletal Radiol. 2015;44(5):667-672.

3. Gordon BH, Chew FS. Isolated acromioclavicular joint pathology in the symptomatic shoulder on magnetic resonance imaging: a pictorial essay. J Comput Assist Tomogr. 2004;28(2):215-222.

4. Warner JJ, Beim GM, Higgins L. The treatment of symptomatic os acromiale. J Bone Joint Surg Am. 1998;80(9):1320-1326.

5. Sammarco VJ. Os acromiale: frequency, anatomy, and clinical implications. J Bone Joint Surg Am. 2000;82(3):394-400.

6. Gruber W. Über die Arten der Acromialknochen und accidentellen Acromialgelenke. Arch Anat Physiol Und wissensch Med. 1863:373-378.

7. Yammine K. The prevalence of Os acromiale: a systematic review and meta-analysis. Clin Anat. 2014;27(4):610-621.

8. Kumar J, Park WH, Kim SH, Lee HI, Yoo JC. The prevalence of os acromiale in Korean patients visiting shoulder clinic. Clin Orthop Surg. 2013;5(3):202-208.

9. Case DT, Burnett SE, Nielsen T. Os acromiale: population differences and their etiological significance. Homo. 2006;57(1):1-18.

10. Hunt DR, Bullen L. The frequency of os acromiale in the Robert J. Terry Collection. Int J Osteoarchaeol. 2007;17:309-317.

11. Natsis K, Tsikaras P, Totlis T, et al. Correlation between the four types of acromion and the existence of enthesophytes: a study on 423 dried scapulas and review of the literature. Clin Anat. 2007;20(3):267-272.

12. Ponce PV.A comparative study of activity-related skeletal changes in 3 rd to 2nd millennium BC coastal fishers and 1st millennium AD inland agriculturists in Chile, South America; 2010. Durham Theses. Durham University. Available from: http://etheses.dur.ac.uk/546/. Accessed December, 2017.

13. Roberts AM, Peters TJ, Brown KR. New light on old shoulders: palaeopathological patterns of arthropathy and enthesopathy in the shoulder complex. J Anat. 2007;211(4):485-492.

14. Edelson JG. Variations in the anatomy of the scapula with reference to the snapping scapula. Clin Orthop Relat Res. 1996;(322):111-115.

15. Nicholson GP, Goodman DA, Flatow EL, Bigliani LU. The acromion: morphologic condition and age-related changes. A study of 420 scapulas. J Shoulder Elbow Surg. 1996;5(1):1-11.

16. Ortiguera CJ, Buss DD. Surgical management of the symptomatic os acromiale. J Shoulder Elbow Surg. 2002;11(5):521-528.
17. Demetracopoulos CA, Kapadia NS, Herickhoff PK, Cosgarea AJ, McFarland EG. Surgical stabilization of os acromiale in a fast-pitch softball pitcher. Am J Sports Med. 2006;34(11):1855-1859.

18. Kawaguchi S, Fukuta S, Tsutsui T, et al. Arthroscopic excision of unstable os acromiale associated with impingement syndrome: a case report. J Med Invest. 2016;63(1-2):131-134.

19. Neer CS 2nd. Impingement lesions. Clin Orthop Relat Res. 1983;(173): $70-77$.

20. Barbier O, Block D, Dezaly C, Sirveaux F, Mole D. Os acromiale, a cause of shoulder pain, not to be overlooked. Orthop Traumatol Surg Res. 2013;99(4):465-472.

21. Lee DH, Lee KH, Lopez-Ben R, Bradley EL. The double-density sign: a radiographic finding suggestive of an os acromiale. J Bone Joint Surg Am. 2004;86-A(12):2666-2670.

22. Johnston PS, Paxton ES, Gordon V, Kraeutler MJ, Abboud JA, Williams GR. Os acromiale: a review and an introduction of a new surgical technique for management. Orthop Clin North Am. 2013;44(4):635-644.

23. Al-faham Z, Jolepalem P. Use of SPECT/CT with 99mTc-MDP bone scintigraphy to diagnose symptomatic os acromiale. J Nucl Med Technol. 2015;43(3):236-237.

24. Stetson WB, McIntyre JA, Mazza GR. Arthroscopic excision of a symptomatic meso-acromiale. Arthrosc Tech. 2017;6(1):e189-e194.

25. Abboud JA, Silverberg D, Pepe M, et al. Surgical treatment of os acromiale with and without associated rotator cuff tears. J Shoulder Elbow Surg. 2006;15(3):265-270.

26. Harris JD, Griesser MJ, Jones GL. Systematic review of the surgical treatment for symptomatic os acromiale. Int J Shoulder Surg. 2011;5(1):9-16.

27. Wright RW, Heller MA, Quick DC, Buss DD. Arthroscopic decompression for impingement syndrome secondary to an unstable os acromiale. Arthroscopy. 2000;16(6):595-599.

28. Atoun E, van Tongel A, Narvani A, Rath E, Sforza G, Levy O. Arthroscopically assisted internal fixation of the symptomatic unstable os acromiale with absorbable screws. J Shoulder Elbow Surg. 2012;21(12):1740-1745.

29. Kurtz CA, Humble BJ, Rodosky MW, Sekiya JK. Symptomatic os acromiale. J Am Acad Orthop Surg. 2006;14(1):12-19.

30. Peckett WR, Gunther SB, Harper GD, Hughes JS, Sonnabend DH. Internal fixation of symptomatic os acromiale: a series of twenty-six cases. J Shoulder Elbow Surg. 2004;13(4):381-385.

31. Spiegl UJ, Smith SD, Todd JN, Wijdicks CA, Millett PJ. Biomechanical evaluation of internal fixation techniques for unstable meso-type os acromiale. J Shoulder Elbow Surg. 2015;24(4):520-526.

32. Campbell PT, Nizlan NM, Skirving AP. Arthroscopic excision of os acromiale: effects on deltoid function and strength. Orthopedics. 2012;35(11):e1601-1605.

33. Pagnani MJ, Mathis CE, Solman CG. Painful os acromiale (or unfused acromial apophysis) in athletes. J Shoulder Elbow Surg. 2006;15(4): 432-435.

34. Pagnani MJ, Speer KP, Altchek DW, Warren RF, Dines DM. Arthroscopic fixation of superior labral lesions using a biodegradable implant: a preliminary report. Arthroscopy. 1995;11(2):194-198.

35. Boehm TD, Matzer M, Brazda D, Gohlke FE. Os acromiale associated with tear of the rotator cuff treated operatively. Review of 33 patients. J Bone Joint Surg Br. 2003;85(4):545-549.

36. Lebus GF, Fritz EM, Hussain ZB, Pogorzelski AJ, Millett PJ. Operative Treatment of Symptomatic Meso-Type Os Acromiale. Arthrosc Tech. 2017;6(4):e1093-e1099.

37. Shiu B, Song X, Iacangelo A, et al. Os acromiale fixation: a biomechanical comparison of polyethylene suture versus stainless steel wire tension band. J Shoulder Elbow Surg. 2016;25(12):2034-2039.

38. Ryu RK, Fan RS, Dunbar WHt. The treatment of symptomatic os acromiale. Orthopedics. 1999;22(3):325-328.

39. Ozbaydar MU, Keris I, Altun M, Yalaman O. [Results of the surgical treatment for symptomatic mesoacromion]. Acta Orthop Traumatol Turc. 2006;40(2):123-129. 
Orthopedic Research and Reviews is an international, peer-reviewed, open access journal that focusing on the patho-physiology of the musculoskeletal system, trauma, surgery and other corrective interventions to restore mobility and function. Advances in new technologies, materials, techniques and pharmacological agents are particularly welcome. The manuscript management system is completely online and includes a very quick and fair peer-review system, which is all easy to use. Visit http://www.dovepress.com/testimonials.php to read real quotes from published authors.

Submit your manuscript here: https://www.dovepress.com/orthopedic-research-and-reviews-journal 